Review of

\title{
Pierre Gouin \\ Trémblements de terre «historiques» au Québec (de 1534 à mars 1925) identifiés et interprétés à partir des textes originaux contemporains
}

by Jean Vogt

Strasbourg, France

In the best tradition of what could be called the Jesuit School of Seismology (e.g. Udías and Stauder, 1996), Pierre Gouin first disentangled complex sources to provide a chef d'oeuvre on Ethiopia's historical seismology (Gouin, 1979). Back in his native Québec he offers us a second essay on a wholly different seismo-tectonic and historical setting. The Province of Québec has a sparse and low seismic activity, known mostly from the lowlands from the midst of the 17th century on; Gouin describes it until 1925, mentioning a «tremor, ... the first, in our opinion, of the seismic instrumental era in the province of Québec», a rather late beginning indeed.

This critical inventory of sources and events is published both in French (even pages) and English (odd pages). Until mid 18th century it is based on unpublished or printed primary sources, partly of ecclesiastic origin, sometimes characterized by an «apocalyptic style» and «oratorical convulsions». From 1764 on, information, though often less reliable, is also found in early newspapers.

A rigorous methodology is implemented with, for instance, critical comments on cata-

Mailing address: Dr. Jean Vogt, Rue du Docteur Woehrlin 1, 67000 Strasburg-Robertsau, France. logues «too often based on secondary sources which are not completely reliable», by means of the example of Smith's catalogue (1962) from the Dominion Observatory, «the quasi-official catalogue of Canadian earthquakes». Indeed Gouin's interpretations are sometimes very different, and Smith's magnitude estimates do not escape criticism, since he used an «equation... valid for California, not for Québec».

While the first pages are introductory and methodological, a catalogue follows, supplying both places affected and some earthquake parameters, such as epicentral intensity (MM scale), epicentral location and magnitude. Some methodological considerations are available here and there.

Gouin uses an arsenal of symbols. So his appraisal of the reliability of the information, a «personal evaluation», is emphasized, with letters $\ll \mathrm{R}$ for real, $\mathrm{P}$ for probable, $\mathrm{p}$ for possible, $\mathrm{d}$ for doubtful, $\mathrm{f}$ for false». Gouin denounces widespread dogmatism, leading sometimes to astonishing and even ridiculous results. Actually he writes «that there is no fixed rule of interpretation for these wordings [used to describe the intensity of earthquakes] and each case is different». While «all known pre-1764 documents were read and annotated», Gouin insists on the fact «that the survey is not exhaustive», avoiding any triumphal attitude. 
This review highlights three events with typical discrepancies in their interpretation. The 1663 sequence, lasting «a minimum of seven months» is the Quebec event par excellence. For the main shock Gouin proposes an intensity $\geq$ VIII Mercalli Modified scale and a magnitude of $6.5 \pm 0.5$. However «the epicentral region is not perfectly known», the one given by Smith (1962) being «doubtful». Historical sources emphasize major seismo-geological effects. Sharper disagreements appear for the 1665 event. Former authors had proposed an intensity VIII, and different magnitudes, but Gouin states that «details are insufficient to determine intensity, an epicentral region and the magnitude». Such problems also arise also with the 1732 earthquake. While an intensity IX had been proposed for Montreal, for Gouin the highest known intensity is no more than «VI ?». Instead of an epicentre near Montreal, Gouin «places the epicentral region in the Adirondacks».

The bulk of Gouin's book is devoted to «Commented documents», with a wealth of remarks on the preceding catalogue, and enriched by maps where the mentioned places are shown, while a complete geographical index is given in Appendix 1. In this section Gouin also discusses some false events, among which the oldest reported ones (1534 or 1535, 1623), with far-off effects of New England events (1638, 1668). Many pages are devoted to the 1663 sequence with a number of systematically discussed testimonies, some of which are dealing with landslides and liquefaction. For one or another event we find more arguments against Smith's propos- als. For 1665, according to Gouin «the location of the epicentre is given with too much precision to be plausible». And for an event in 1768, relocated in the Adirondacks, he says that «the determination of an intensity of VI [MM] and the location of an epicentre are not justified by the primary documents».

Of great interest is the discussion of the faroff and isolated testimonies from Abitibi House Post (1811) and even earlier from the Hudson Bay $(1764,1782)$. Luckily Gouin does not discard such minor events, of great seismo-tectonic interest; but in some cases (e.g., 1764 and 1811) he compares the historical evidence with that emerging from the instrumentally located epicentres between 1970 and 1984.

Long hours should be spent with Gouin's book, not only for its specific achievements, but also for his outstanding contribution to the methodology of historical seismology.

\section{REFERENCES}

GouIn, P. (1979): Earthquake History of Ethiopia and the Horn of Africa (International Development Research Centre, Ottawa), pp. 259.

GouIn, P. (2001): Trémblements de terre «historiques» au Québec (de 1534 à mars 1925) identifiés et interprétés à partir des textes originaux contemporains («Historical» earthquakes felt in Québec (from 1534 to March 1925) as revealed by the local contemporary literature) (Guérin, Montreal), pp. 1491.

SMith, W.E.T. (1962): Earthquake of Eastern Canada and Adjacent Areas, 1534-1927, Publications of the Dominion Observatory, Ottawa, 26 (5), 271-301.

UdíAs, A. and W. STAUDER (1996): The Jesuit contribution to seismology, Seismol. Res. Lett., 67 (3), 10-19. 